\title{
Numerical simulation of laser bending of AISI 304 plate with a rectangular cut out
}

\author{
K. Paramasivan ${ }^{1}$, S. Das ${ }^{2}$, M. Sundar ${ }^{3}$, D. Misra ${ }^{4}$ \\ ${ }^{I *}$ School of Laser science and Engineering, Jadavpur University Kolkata, INDIA \\ ${ }^{2}$ Mechanical Engineering Department, Jadavpur University Kolkata, INDIA \\ ${ }^{3}$ School of Mechanical and Manufacturing, Loughborough University Leicestershire, UK \\ ${ }^{4}$ School of Laser science and Engineering, Jadavpur University Kolkata, INDIA \\ *Corresponding Author: e-mail: parma.gce@gmail.com, Tel +91 3324146372, Fax.+91-332-3376331
}

\begin{abstract}
This paper presents investigation of laser bending of AISI 304 plate having a rectangular cut out at its middle via process modeling by finite element method and statistical techniques. The objective is to study the effects of process and geometric parameters on thermal and deformation fields. Correlations are developed, with satisfactory accuracy, to predict maximum temperature and bending angle in the form of second order equations using response surface methodology. Artificial Neural Network models are also developed to predict maximum temperature and bending angle. Results indicate that maximum temperature and bending angle increases with laser power and decreases with increase in scanning speed. Moreover, bending angle decreases with increase in cut out dimension along laser scanning path due to the reduced interaction time between the work piece and the laser beam. Predictions from regression models and neural network models are compared with simulation results and performance of both approaches are found to be satisfactory.
\end{abstract}

Keywords: laser bending; process modeling; bending angle; response surface models.

DOI: http://dx.doi.org/10.4314/ijest.v9i1.1

\section{Introduction}

Laser forming is an emerging technology in diverse manufacturing industries, such as, automobile, shipbuilding, aerospace, micro electronics etc. Laser forming is realized by introducing residual thermal stress in the component under consideration. The internal stress induce plastic strain to yield bending in the component. In contrast to conventional techniques, laser bending requires no physical contact and possesses the inherent advantage of process flexibility associated with laser manufacturing techniques.

Extensive studies have been undertaken in the area of laser forming process to explore the process and geometrical parameters using experimental and numerical techniques. The temperature field is simulated by ( $\mathrm{Ji}$ and $\mathrm{Wu}, 1998)$. In their following work, (Wu and Ji, 2002) presented the deformation field during laser forming. (Kyrsanidi et al., 1999) presented their results for laser forming process of metallic plates. (Cheng et al., 2004) presented the effects of geometry, including sheet width and length on deformation. They found that the bending increases with the sheet dimension along scanning path and sheet dimension across the scanning path has little effect on bending angle. (Shi et al., 2007) presented numerical simulation of bending for with different shapes of laser beam such as circular, square and rectangular. (Gollo et al, 2010) presented numerical and experimental studies with DoE technique to characterize the effects of process parameters on deformation. They have found that bending angle depends on beam diameter, pulse duration, scan velocity and laser power in diminishing order of significance. (Venkadeshwaran et al., 2012) used FEM and RSM to predict bending angle and optimise process parameters for bending of stainless steel. They have identified optimised parameters to increase productivity, reduce operating cost and HAZ. (Zahrani and Marasi, 2013) experimentally investigated role of process parameters on edge effect and longitudinal distortion during laser bending. Their 
results indicate that edge effect and longitudinal distortion decreases with increase in sheet thickness, scan speed and laser power and decrease in beam diameter. (Maji et al., 2013) presented experimental investigation of bending with pulsed laser to explore the effect of process parameters. (Shichun and Jinsong, 2001) studied the effect of line energy, material properties and sheet geometry on bending angle. Their results show that bending angle decreases sharply with increase in sheet thickness. (Chen et al., 2004) investigated the effects of deformation parameters on bending angle for Ti-6Al-4V alloy sheets. They observed that bending angle decreases with increase in sheet thickness and increases with sheet width. (Nadeem and Na, 2011) studied the deformation behavior different specimen geometries such as rectangular, circular and ring shape. They found that linear irradiation paths for rectangular plates have more deformation than curved irradiation paths for ring and circular specimens.

So far, Laser bending of rectangular plates have been studied extensively by many researchers. However, many applications require bending of rectangular plates with a rectangular cut out at its middle. Forming of such parts, with rectangular cut out, is extensively used in automotive industries. The front and rear panels in car bodies have this type of cut out geometries requiring sheet bending. The cut outs are required for fitting bulb housings, creation of opening for mounting air grills for radiator, etc. Rectangular plates with central cut out have not been studied till date with the exception of (Shen et al., 2012). The present paper makes an in-depth study of the effects of process parameters on the bending of AISI 304 plates. The present work further investigates the effects of variation of the dimensions of the rectangular cut out on the final bending. The present work also investigates the effects of process parameters on temperature distribution and deformation on laser bending of AISI 304 plate metal with rectangular cut out at its center through finite element method and response surface methodology. COMSOL/MATLAB programming code is used to develop the finite element model.

\section{Finite Element Simulation}

The workpiece dimension used in the study is of $100 \times 50 \times 1.5 \mathrm{~mm}^{3}$. To investigate the effects of rectangular cut out and laser process parameters, namely, power, scanning speed and their interactions on temperature distribution and final bending angle, different dimensions of cut out and process parameters are chosen for the present numerical simulation. Figure 1 shows a typical work piece, scanning direction and fixed end of the plate. The simply-supported boundary conditions are applied at the fixed end of the plate, and other ends are free. A laser beam traverses along the middle of the plate along the y-axis. The laser beam is modeled as a moving surface heat flux.

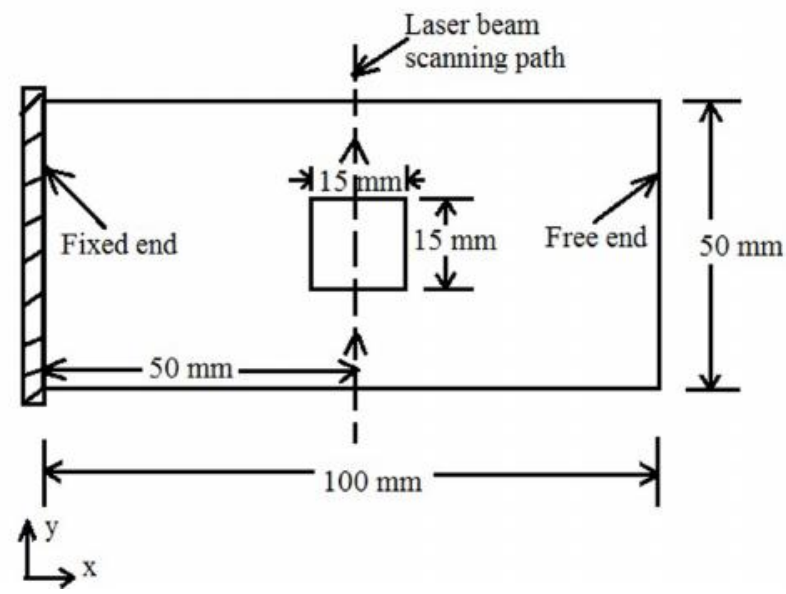

Figure 1: Schematic diagram of the work piece

A 3-D free tetrahedral mesh is used in this numerical modeling. The temperature gradient and the stress gradient around the laser scanning path are high and therefore, require a denser mesh. A non-uniform mesh pattern is used to reduce simulation time and memory requirement. Figure 2 shows, typical mesh pattern used for numerical modeling.

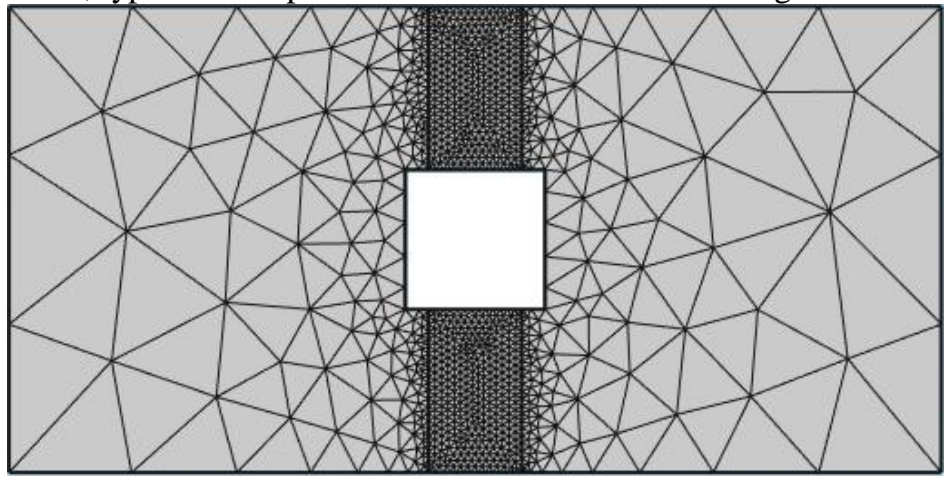

Figure 2: Finite element mesh used for modeling 
Following assumptions are made for simulation of the process:

1. Material properties of the work piece are isotropic.

2. Laser intensity follows a Gaussian distribution.

3. Within the work piece, heat transfer takes place by conduction obeying Fourier's law and heat loss by free convection and radiation are considered from the surfaces of the plate metal to the surrounding.

4. Melting is not involved in the work piece during laser forming process, so phase changes and heat generation are neglected.

5. von-Mises yield criterion is considered in the bending process.

\subsection{Governing Equations and Boundary Conditions}

Following three-dimensional heat conduction equation within the specimen is considered

$$
\rho c \frac{\partial T(\boldsymbol{r}, t)}{\partial t}=k \nabla_{r .}\left(\nabla_{r} T\right)
$$

where $\rho$ is material density $\left(\mathrm{kg} / \mathrm{m}^{3}\right), c$ is specific heat $\left(\mathrm{J} / \mathrm{kg}{ }^{\circ} \mathrm{C}\right), k$ is thermal conductivity $\left(\mathrm{W} / \mathrm{m}^{\circ} \mathrm{C}\right), T(\boldsymbol{r}, t)$ is the temperature $(\mathrm{K}), \boldsymbol{r}$ is the coordinate $(\mathrm{m})$ in the reference configuration, $t$ is time (s) and $\nabla_{r}$ is the gradient operator.

Material cooling phase is made through natural convection and radiation from its surfaces exposed to ambient air and expressed through following boundary conditions.

$$
\begin{aligned}
& q_{\text {conv }}=h\left(T_{s}-T_{o}\right) \\
& q_{\text {rad }}=\varepsilon \sigma\left(T_{s}^{4}-T_{o}^{4}\right)
\end{aligned}
$$

where, $h$ is heat transfer coefficient, which is taken as $\left(10 \mathrm{~W} / \mathrm{m}^{2} \mathrm{~K}\right), T_{s}$ is plate metal surface temperature and $T_{0}$ is the ambient temperature, which is taken as $300 \mathrm{~K}, \boldsymbol{\varepsilon}$ is emissivity and $\sigma$ is Stefan Boltzmann constant $\left(5.6703 \times 10^{-8} \mathrm{~W} / \mathrm{m}^{2} \mathrm{~K}^{4}\right)$.

\subsection{Heat Flux}

The moving heat flux $Q$ is applied along the scanning path with a Gaussian distribution and expressed as follows:

$$
Q=\frac{2 A P}{\pi R^{2}} \exp \left(-\frac{2 r^{2}}{R^{2}}\right)
$$

where, $A$ is the absorption coefficient, $P$ is laser power $(\mathrm{W}), R$ is beam radius (m) and $r$ is distance (m) of a point from beam centre.

\subsection{Material Properties}

The material AISI 304 stainless steel is used in this numerical study. Stress-strain behavior is expressed through bi-linear curves. The temperature dependent material properties are taken from (Che et al, 2011). Elasto-plastic properties (Paramasivan et al., 2014) also used in the present analysis.

\subsection{Validation of Finite Element Model}

To validate the capability of the current simulation, results are compared with published results of (Venkadeshwaran et al, 2012) and (Jung, 2006). The materials used are AISI 304 and Ship-building steel 1.0584 (D36) for validation. The plate size and process parameters are taken from their work for validation. Two bend angle histories and two temperature histories obtained from the simulations are compared to the experimental results reported by (Jung, 2006). In the present model, the temperature reaches a maximum of $722^{\circ} \mathrm{C}$ at plate centre during heating. (Jung, 2006) have achieved maximum of $728^{\circ} \mathrm{C}$ at plate centre. Table 1

\begin{tabular}{|c|c|c|c|c|c|c|}
\hline \multicolumn{4}{|c|}{ Parameter } & \multicolumn{2}{|c|}{ Temperature at plate centre $\left({ }^{\circ} \mathbf{C}\right)$} & \multirow[b]{2}{*}{$\begin{array}{l}\text { Percentage } \\
\text { Error } \\
\frac{\left(\phi_{t}-\phi_{s}\right)}{\left(\phi_{s}\right)} \times 100\end{array}$} \\
\hline $\begin{array}{l}\text { Laser } \\
\text { power } \\
{[\mathrm{W}]}\end{array}$ & $\begin{array}{l}\text { Scanning } \\
\text { speed } \\
{[\mathrm{mm} / \mathrm{s}]}\end{array}$ & $\begin{array}{l}\text { Spot } \\
\text { diameter } \\
{[\mathrm{mm}]}\end{array}$ & $\begin{array}{l}\text { Plate } \\
\text { thickness } \\
{[\mathrm{mm}]}\end{array}$ & $\operatorname{Present}\left(\phi_{t}\right)$ & $\left(\right.$ Jung, 2006) $\left(\phi_{s}\right)$ & \\
\hline 1500 & 5 & 16 & 6 & 722 & 728 & -0.82 \\
\hline 3000 & 10 & 16 & 4 & 903 & 844 & 6.99 \\
\hline
\end{tabular}
summarises the input parameters, the simulation results of temperature field and percentages of error for validation with published work of (Jung, 2006).

Table 1: Validation of temperature field 
Table 2 summarises the input parameters, the simulation results of bending angle and percentages of error with published work of (Venkadeshwaran et al., 2012) and (Jung, 2006). Bend angles and thermal fields achieved from the present simulations are found to be in close agreement with those from the both references (Venkadeshwaran et al., 2012) and (Jung, 2006).

Table 2: Validation of deformation field

\begin{tabular}{|l|l|l|l|l|l|l|l|}
\hline \multicolumn{4}{|c|}{ Parameter } & \multicolumn{3}{l|}{ Bending angle (degrees) } & Percentage Error \\
\hline $\begin{array}{l}\text { Laser } \\
\text { power } \\
{[\mathrm{W}]}\end{array}$ & $\begin{array}{l}\text { Scanning } \\
\text { speed } \\
{[\mathrm{mm} / \mathrm{s}]}\end{array}$ & $\begin{array}{l}\text { Spot } \\
\text { diameter } \\
{[\mathrm{mm}]}\end{array}$ & $\begin{array}{l}\text { Plate } \\
\text { thickness } \\
{[\mathrm{mm}]}\end{array}$ & Present $\left(\phi_{p}\right)$ & $\begin{array}{l}(\text { Venkadeshw } \\
\text { aran et al, } \\
2012)\left(\phi_{v}\right)\end{array}$ & $\begin{array}{l}(\text { Jung, 2006) } \\
\left(\phi_{v}\right)\end{array}$ & $\begin{array}{l}\left(\phi_{p}-\phi_{v}\right) \\
\left(\phi_{v}\right)\end{array} \times 100$ \\
\hline 125 & 20 & 2 & 1.5 & 0.0975 & 0.101 & ------- & -3.46 \\
\hline 375 & 20 & 2 & 1.5 & 1.2044 & 1.257 & ------ & -4.18 \\
\hline 1500 & 5 & 16 & 6 & 0.468 & ------ & 0.47 & -0.42 \\
\hline 3000 & 10 & 16 & 4 & 1.41 & ------ & 1.32 & 6.81 \\
\hline
\end{tabular}

\section{Results and Discussion}

In this segment, the temperature distribution and deformation field of AISI 304 plate with $15 \times 15 \mathrm{~mm}^{2}$ cut out is presented at different time intervals for laser power of $375 \mathrm{~W}$, scanning speed of $10 \mathrm{~mm} / \mathrm{s}$, spot diameter of $2 \mathrm{~mm}$ and plate thickness $1.5 \mathrm{~mm}$ as a typical case within the range of study.

\subsection{Transient Temperature and Deformation Fields of a Plate}

Figure 3 shows the temperature distributions of the plate at three instances: (a) when the laser beam is before the cut out (at $t=1.6$ $\mathrm{s}$ ), (b) when the laser beam is at the farthest edge of the plate (at $t=5.6 \mathrm{~s}$ ) and (c) after $30 \mathrm{~s}$. During heating, peak temperature of $1702 \mathrm{~K}$ is reached at the farthest point on the scanning line. After $30 \mathrm{~s}$, the temperature drops further in the range of 300 to $339 \mathrm{~K}$.

a

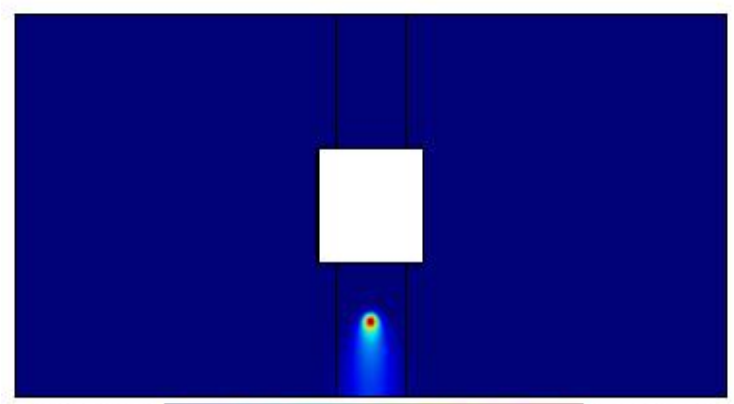

$\mathbf{\nabla} 293.11$

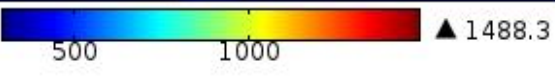

c

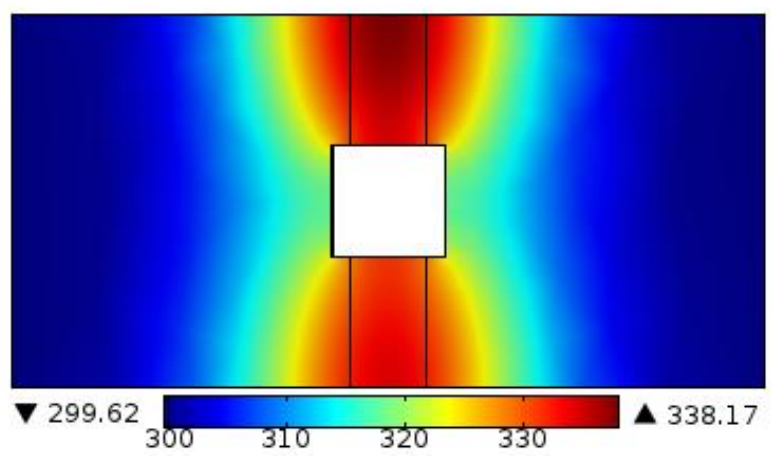

Figure 3: Temperature distribution at three instances: (a) beam is before the cut out, (b) beam is at plate end, (c) after cooling (laser power $=375 \mathrm{~W}$, scanning speed $=10 \mathrm{~mm} / \mathrm{s}$, beam diameter $=2 \mathrm{~mm}$, plate thickness $=1.5 \mathrm{~mm}$ ) 


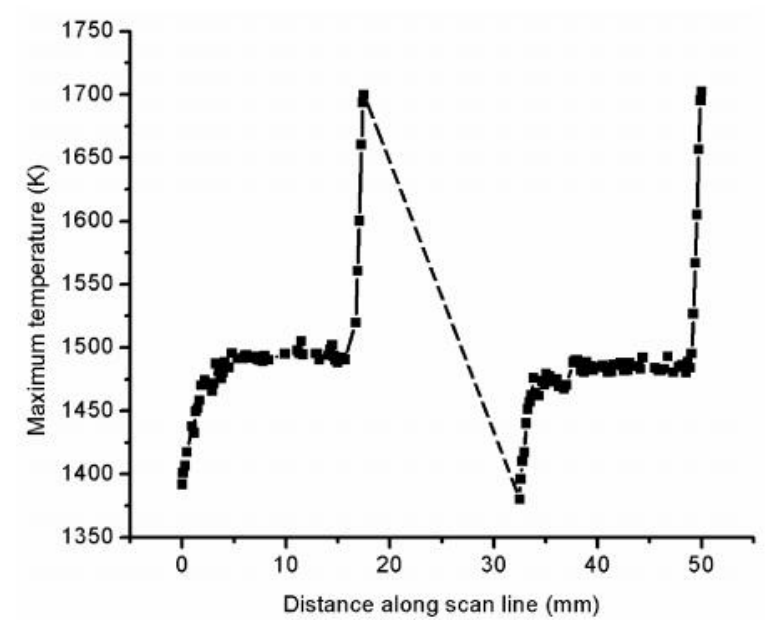

Figure 4: Maximum temperature along the scan line

The maximum temperature observed along the scan line of the plate is shown in Figure 4. It can be seen from the figure that the temperature starts rising gradually on the top surface and reaches a steady maximum in the initial stage of heating. The temperature increases rapidly when the beam approaches the cut out. The reason for this is that heat deposited by the laser beam and the heat retained by the material behind the beam is conducted into the cold region ahead of the beam, and as the beam reaches the cut out edge the heat flowing ahead of the beam can only be transported to the surrounding air by convection through the cut out surface at a much slower rate as air is a poor dissipater of heat. Hence, a heat buildup occurs at the edge of the cut out with a consequent rise in temperature. The plate attains a maximum temperature when laser beam reaches the upper edge of the plate due to a similar reason. The nature of maximum temperature variation from the start of the plate to the starting edge of the cutout is identical to the variation of maximum temperature from the farthest edge of the cutout to the end of the plate, as may be observed in Figure 4. The small differences in maximum temperature, on a point to point basis in the lower and upper parts of the plate, varies from a minimum of $0.001 \%$ to a maximum of $2.32 \%$, and the same can be attributed to numerical inaccuracy.

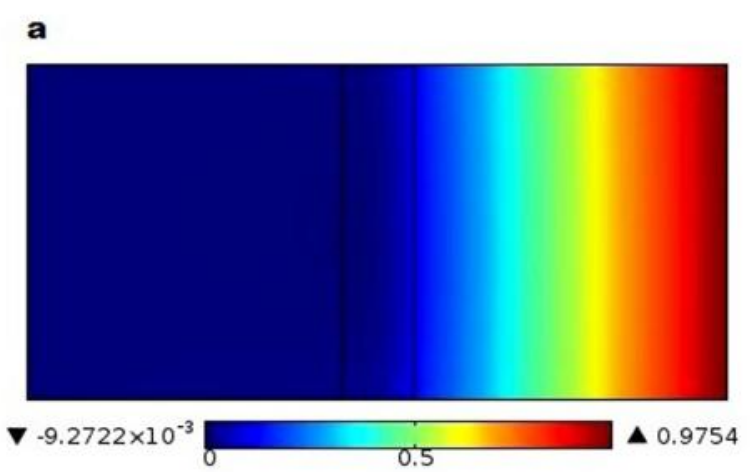

c

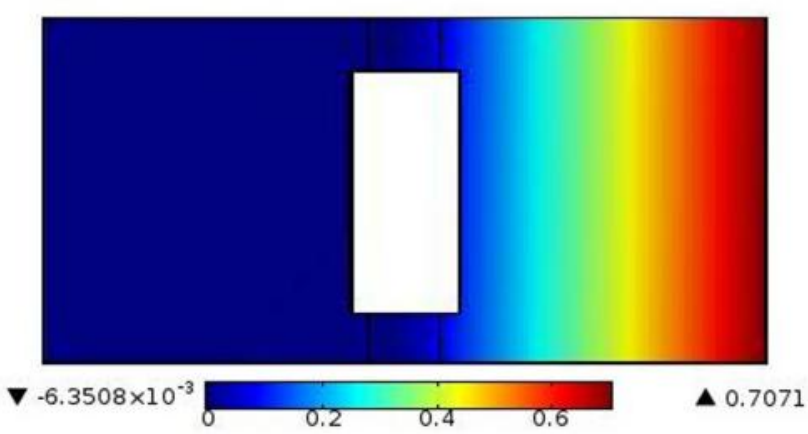

b
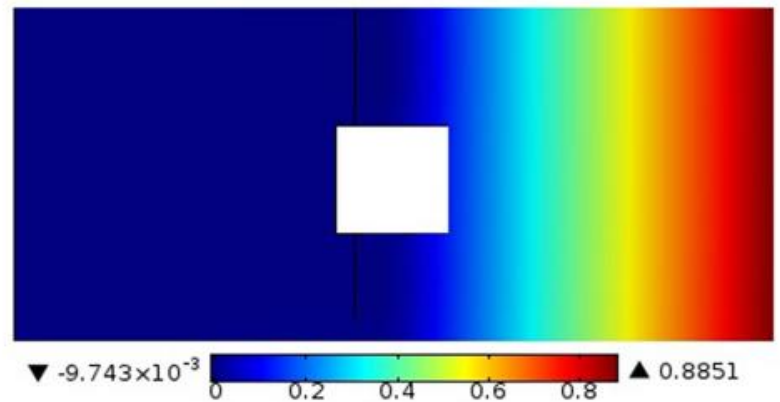

d

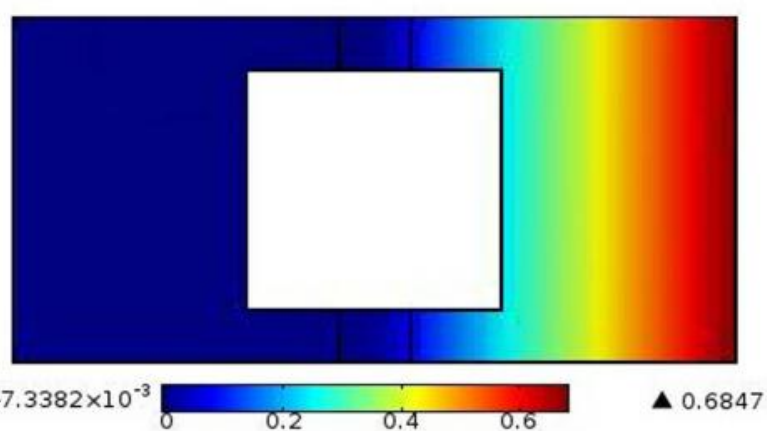

Figure 5: z-component of displacement (mm) after $30 \mathrm{~s}$ : (a) full plate, (b) $15 \times 15 \mathrm{~mm}^{2}$ cut out plate, (c) $15 \times 35 \mathrm{~mm}{ }^{2}$ cut out plate, (d) $35 \times 35 \mathrm{~mm}^{2}$ cut out plate (laser power $=375 \mathrm{~W}$, scanning speed $=10 \mathrm{~mm} / \mathrm{s}$, plate thickness $=1.5 \mathrm{~mm}$, beam diameter $=2 \mathrm{~mm}$ ) 
Figures 5 (a-d) show the variation of z-displacement for different size of the cutouts after 30 s. It can be seen that under the conditions of same process parameters, displacement is varying depending upon the size of the cutout. The maximum out of plane displacement (along $\mathrm{z}$ ) is achieved for a full plate without cutout followed by $15 \times 15 \mathrm{~mm}^{2}$ cut out plate, $15 \times 35 \mathrm{~mm} \mathrm{~m}^{2}$ cut out plate and $35 \times 35 \mathrm{~mm}^{2}$ cut out plate. It is evident from these figures, that $\mathrm{z}$-displacement decreases with the depth of cut out and width of cut out has little effect on bending angle. The reason for this is that the sample without cutout has more heating time, receiving maximum amount of energy. So, a greater thermal stress and plastic strain develop in the region of the scanning path compared to the plates with cutout.

\subsection{Response Surface Methodology}

Response surface methodology is a set of mathematical and statistical techniques that are useful for empirical model and optimization. A model predicting the response for some independent input variables can be obtained by conducting experiments and applying regression analysis (Acherjee et al, 2012) and (Montgomery, 2001). If all independent parameters are measurable, the response surface can be expressed as:

$$
y=f_{r}\left(x_{1}, x_{2}, x_{3}, \ldots . . x_{n}\right) \pm \varepsilon_{e r}
$$

where $y$ is the response, $f_{r}$ is the function of response, $\varepsilon_{e r}$ is the experimental error, and $\left(x_{1}, x_{2}, x_{3}, \ldots . . x_{n}\right)$ are independent parameters. The application of response surface method is to use a series of designed experiments to find an approximate relationship between a response and a number of input variables, based on the observed data. In the present work, response is collected from numerical simulation for laser bending of AISI 304 plate with a cut out at its middle after one laser pass. The process parameters (low actual and high actual) and their notation and units are presented in Table 3.

Table 3: Process parameters and their units and limits

\begin{tabular}{|l|l|l|l|l|}
\hline Parameter & Notation & Unit & Low actual & High actual \\
\hline Laser power & $P$ & $\mathrm{~W}$ & 275 & 375 \\
\hline Scanning speed & $V$ & $\mathrm{~mm} / \mathrm{s}$ & 10 & 20 \\
\hline $\begin{array}{l}\text { Cut out dimension in } \\
\text { x-direction }\end{array}$ & $X$ & $\mathrm{~mm}$ & 15 & 35 \\
\hline $\begin{array}{l}\text { Cut out dimension in } \\
\text { y-direction }\end{array}$ & $Y$ & $\mathrm{~mm}$ & 15 & 35 \\
\hline
\end{tabular}

Further, numerical simulations are carried out using the developed FEA model as per the design layout furnished in Table 3. The choice of laser parameter ranges are based on the criteria that the plate attained significant bending, yet the material did not attain melting temperature. The maximum temperature and deformation of the plate as responses are listed in Table 4.

Table 4: Design layout and responses from simulation

\begin{tabular}{|c|c|c|c|c|c|c|}
\hline \multirow[t]{2}{*}{ Sl. No } & \multicolumn{4}{|c|}{ Process parameters } & \multicolumn{2}{|l|}{ Responses } \\
\hline & $P(\mathrm{~W})$ & $V(\mathrm{~mm} / \mathrm{s})$ & $X(\mathrm{~mm})$ & $Y(\mathrm{~mm})$ & $\begin{array}{l}\text { Maximum } \\
\text { temperature } \\
T_{\max }(\mathrm{K})\end{array}$ & $\begin{array}{l}\text { Bending angle } \\
\alpha_{b} \text { (deg) }\end{array}$ \\
\hline 1 & 325 & 15.0 & 25.0 & 43.2 & 1451 & 0.233 \\
\hline 2 & 275 & 20.0 & 15.0 & 35.0 & 1203 & 0.249 \\
\hline 3 & 325 & 5.9 & 25.0 & 25.0 & 1726 & 0.970 \\
\hline 4 & 325 & 15.0 & 25.0 & 25.0 & 1424 & 0.550 \\
\hline 5 & 375 & 20.0 & 35.0 & 15.0 & 1456 & 0.588 \\
\hline 6 & 275 & 10.0 & 15.0 & 15.0 & 1397 & 0.609 \\
\hline 7 & 325 & 15.0 & 25.0 & 25.0 & 1424 & 0.550 \\
\hline 8 & 375 & 10.0 & 35.0 & 15.0 & 1701 & 0.963 \\
\hline 9 & 375 & 20.0 & 15.0 & 35.0 & 1459 & 0.495 \\
\hline 10 & 375 & 20.0 & 15.0 & 15.0 & 1458 & 0.600 \\
\hline 11 & 275 & 10.0 & 35.0 & 35.0 & 1397 & 0.420 \\
\hline 12 & 275 & 20.0 & 15.0 & 15.0 & 1202 & 0.317 \\
\hline 13 & 275 & 20.0 & 35.0 & 35.0 & 1201 & 0.239 \\
\hline
\end{tabular}


Table 4 (cont'd): Design layout and responses from simulation

\begin{tabular}{|c|c|c|c|c|c|c|}
\hline \multirow[t]{2}{*}{ Sl. No } & \multicolumn{4}{|c|}{ Process parameters } & \multicolumn{2}{|l|}{ Responses } \\
\hline & $P(\mathrm{~W})$ & $V(\mathrm{~mm} / \mathrm{s})$ & $X(\mathrm{~mm})$ & $Y(\mathrm{~mm})$ & $\begin{array}{l}\text { Maximum } \\
\text { temperature } \\
T_{\max }(\mathrm{K})\end{array}$ & $\begin{array}{l}\text { Bending angle } \\
\alpha_{b} \text { (deg) }\end{array}$ \\
\hline 14 & 325 & 15.0 & 25.0 & 25.0 & 1424 & 0.550 \\
\hline 15 & 325 & 15.0 & 43.2 & 25.0 & 1418 & 0.539 \\
\hline 16 & 325 & 15.0 & 25.0 & 25.0 & 1424 & 0.550 \\
\hline 17 & 234 & 15.0 & 25.0 & 25.0 & 1163 & 0.266 \\
\hline 18 & 275 & 10.0 & 15.0 & 35.0 & 1398 & 0.457 \\
\hline 19 & 375 & 10.0 & 15.0 & 35.0 & 1703 & 0.810 \\
\hline 20 & 325 & 15.0 & 25.0 & 25.0 & 1424 & 0.550 \\
\hline 21 & 325 & 15.0 & 25.0 & 25.0 & 1424 & 0.550 \\
\hline 22 & 375 & 10.0 & 35.0 & 35.0 & 1702 & 0.735 \\
\hline 23 & 375 & 10.0 & 15.0 & 15.0 & 1702 & 1.014 \\
\hline 24 & 275 & 10.0 & 35.0 & 15.0 & 1396 & 0.566 \\
\hline 25 & 275 & 20.0 & 35.0 & 15.0 & 1200 & 0.291 \\
\hline 26 & 325 & 15.0 & 25.0 & 6.8 & 1425 & 0.593 \\
\hline 27 & 325 & 15.0 & 6.8 & 25.0 & 1415 & 0.573 \\
\hline 28 & 375 & 20.0 & 35.0 & 35.0 & 1457 & 0.458 \\
\hline 29 & 416 & 15.0 & 25.0 & 25.0 & 1667 & 0.868 \\
\hline 30 & 325 & 24.1 & 25.0 & 25.0 & 1272 & 0.352 \\
\hline
\end{tabular}

The final mathematical model for maximum temperature as a function of process parameters and cut out dimensions is obtained through Design-Expert ${ }^{\circledR} 7.0$ :

$T_{\max }=624.17281+4.60517 \times P-32.27895 \times V+1.88822 \times X-1.15875 \times Y-0.049000 \times P \times V$

$-5.00000 \times 10^{-3} \times V \times X-1.65484 \times 10^{-3} \times P^{2}+0.84889 \times V^{2}-0.036842 \times X^{2}+0.028065 \times Y^{2}$

The model F-value of 569.72 indicates the model is significant, with only $0.01 \%$ chance that a 'model F-value' this large could occur due to noise. The ANOVA table of the quadratic model with other adequacy measures are listed in Table 5. Normally, $R^{2}$ value varies from 0 to 1 . The $R^{2}$ value is 0.99 for predicted regression model, which is very close to 1 , and is representing that this regression model has good predictive capability.

Table 5: ANOVA for response surface quadratic model of maximum temperature

\begin{tabular}{|c|c|c|c|c|c|c|}
\hline Source & $\begin{array}{l}\text { Sum of } \\
\text { Squares }\end{array}$ & $\begin{array}{l}\text { Degrees } \\
\text { of } \\
\text { freedom }\end{array}$ & $\begin{array}{l}\text { Mean } \\
\text { squares }\end{array}$ & F-value & $\mathrm{p}$-value & \\
\hline Model & 750345.6 & 14 & 53596.11 & 569.7189 & $<0.0001$ & significant \\
\hline $\mathrm{P}$ & 441714 & 1 & 441714 & 4695.356 & $<0.0001$ & \\
\hline V & 295642.1 & 1 & 295642.1 & 3142.633 & $<0.0001$ & \\
\hline PV & 2401 & 1 & 2401 & 25.52228 & 0.0001 & \\
\hline$V^{2}$ & 9323.156 & 1 & 9323.156 & 99.10379 & $<0.0001$ & \\
\hline \multicolumn{4}{|c|}{$\begin{array}{l}\text { Standard deviation }=9.69921 \\
\text { Mean= } 1437.1 \\
\begin{array}{l}\text { Coefficient of variation }=0.674915 \\
\text { Predicted residual error of sum of squares } \\
(\text { PRESS })=7603.404\end{array}\end{array}$} & \multicolumn{3}{|c|}{$\begin{array}{l}R^{2}=0.998123 \\
\text { Adjusted } R^{2}=0.996371 \\
\text { Predicted } R^{2}=0.989886 \\
\text { Adequate precision }=80.62916\end{array}$} \\
\hline
\end{tabular}

The associated p-value of less than 0.05 suggests that model terms are significant. ANOVA results show that the effect of laser power $(P)$, scanning speed $(V)$, the quadratic effect of the square of scanning speed $\left(V^{2}\right)$ and the two level interaction of laser 
power and scanning speed $(P \times V)$ are the most significant model terms for maximum temperature of the plate. The other model terms are not significant and, hence, those can be eliminated to improve model adequacy. But in this present study, non-significant terms are not eliminated from the final regression equation. The final regression equation has good prediction rate without eliminating non-significance terms.

\subsection{Effect of Process Parameters on Maximum Temperature}

The effects of parameters on the response are identified through the developed response surface model. Figure 6 (a) shows the response contour plot of the effect of the interaction between process variables (laser power and scanning speed) on maximum temperature. From the plot, it is observed that maximum temperature increases with laser power for a scanning speed. However, with increase in scanning speed for fixed laser power, maximum temperature decreases. Figure 6 (b) shows the response contour plot of the effect of interaction between geometric parameters of the rectangular cutout (length and width) on maximum temperature. It is observed from the figure that cut out dimensions in both directions have little effect on maximum temperature of the plate. Figure 6 (c) and 6 (d) show the response contour plot and surface plot regarding the effect of interaction between process parameter, laser power and geometric parameter, cutout width on maximum temperature. We observe that maximum temperature increases with laser power and is negligibly affected by the cutout width, corroborating our observations from Figure 6(a) and 6(b).
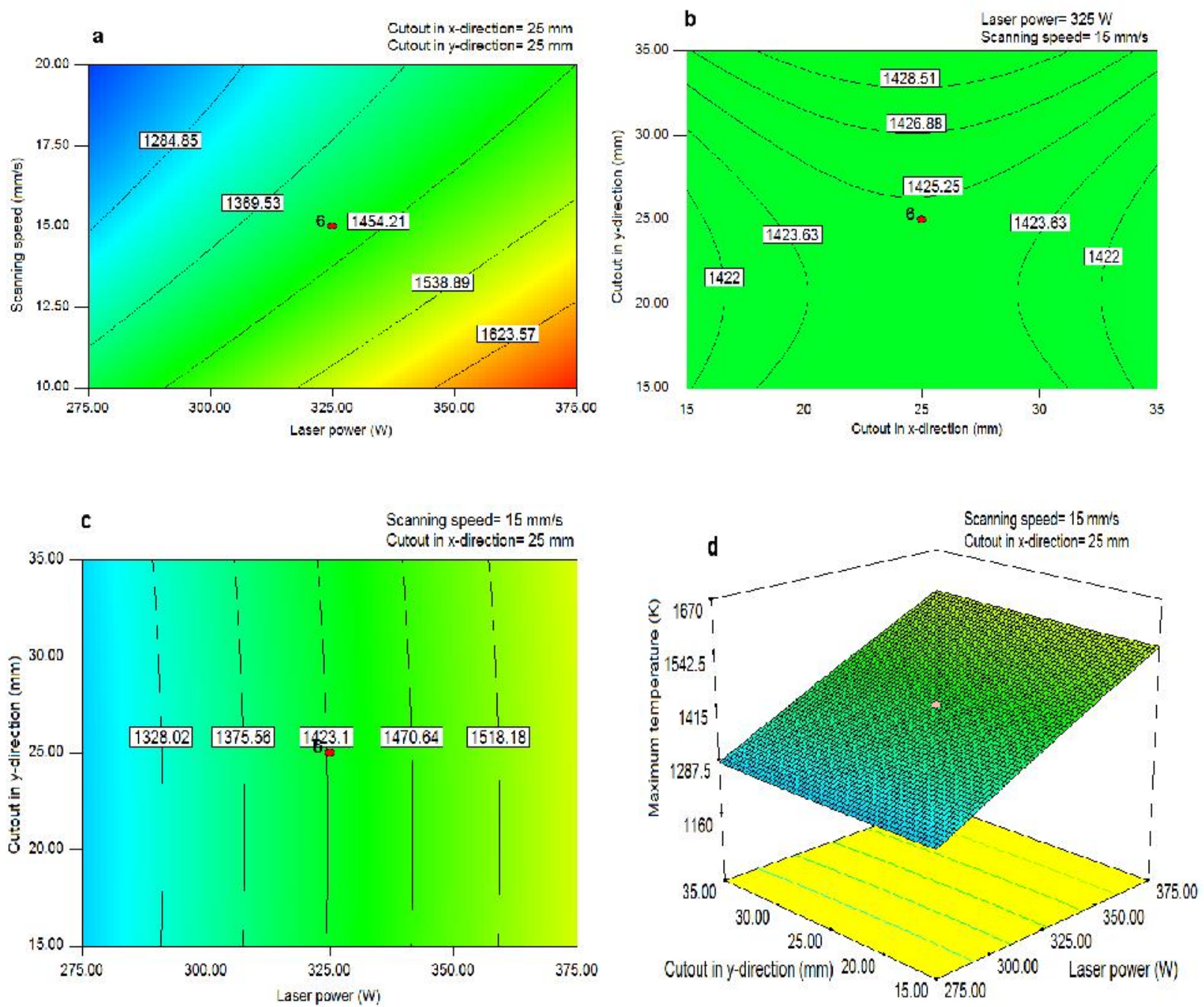

Figure 6: Contour plots and response surface plot showing effects of input parameters on maximum temperature

The model F-value of 172.68 indicates the model is significant, with only $0.01 \%$ chance that a 'model F-value' this large could occur due to noise. The ANOVA table of the quadratic model with other adequacy measures are listed in Table 6 . The $R^{2}$ value is 0.99 for predicted regression model, representing that this regression model has greater predictive capability. The associated $\mathrm{p}-$ value of less than 0.05 for the model indicate model terms are significant. The ANOVA results show that the effect of laser power $(P)$, scanning speed $(V)$, cut out in x-direction $(X)$, cut out in y-direction $(Y)$ and the quadratic effects of scanning speed $\left(V^{2}\right)$, cut out in y-direction $\left(Y^{2}\right)$ and the two level interaction of laser power and scanning speed $(P \times V)$, laser power and cut out in y- 
direction $(P \times Y)$, scanning speed and cut out in y-direction $(V \times Y)$ are the most significant model terms associated with maximum bending angle of the plate.

Table 6: ANOVA of response surface quadratic model for bending angle

\begin{tabular}{|c|c|c|c|c|c|c|}
\hline Source & $\begin{array}{l}\text { Sum of } \\
\text { squares }\end{array}$ & $\begin{array}{l}\text { Degrees } \\
\text { of } \\
\text { freedom }\end{array}$ & $\begin{array}{l}\text { Mean } \\
\text { squares }\end{array}$ & F- value & p-value & \\
\hline Model & 1.33275 & 14 & 0.095196 & 172.6837 & $<0.0001$ & Significant \\
\hline$P$ & 0.576272 & 1 & 0.576272 & 1045.342 & $<0.0001$ & \\
\hline $\mathrm{V}$ & 0.529448 & 1 & 0.529448 & 960.4039 & $<0.0001$ & \\
\hline $\mathrm{X}$ & 0.005499 & 1 & 0.005499 & 9.974155 & 0.0065 & \\
\hline$Y$ & 0.133832 & 1 & 0.133832 & 242.7677 & $<0.0001$ & \\
\hline PV & 0.011299 & 1 & 0.011299 & 20.49612 & 0.0004 & \\
\hline PY & 0.003812 & 1 & 0.003812 & 6.914757 & 0.0189 & \\
\hline VY & 0.00876 & 1 & 0.00876 & 15.89062 & 0.0012 & \\
\hline $\mathrm{V}^{2}$ & 0.023796 & 1 & 0.023796 & 43.16585 & $<0.0001$ & \\
\hline $\mathrm{Y}^{2}$ & 0.034561 & 1 & 0.034561 & 62.6927 & $<0.0001$ & \\
\hline \multicolumn{4}{|c|}{$\begin{array}{l}\text { Standard deviation }=0.023479 \\
\text { Mean }=0.550179 \\
\text { Coefficient of variation }=4.267571 \\
\text { Predicted residual error of sum of squares } \\
(\text { PRESS })=0.045031\end{array}$} & \multicolumn{3}{|c|}{$\begin{array}{l}\mathrm{R}^{2}=0.993834 \\
\text { Adjusted } \mathrm{R}^{2}=0.988078 \\
\text { Predicted } \mathrm{R}^{2}=0.96642 \\
\text { Adequate precision }=48.79678\end{array}$} \\
\hline
\end{tabular}

The final mathematical model for bending angle as a function of process parameters and cut out dimensions is obtained through Design-Expert ${ }^{\circledR} 7.0$ :

$$
\begin{aligned}
& \alpha_{b}=-0.10949+4.31367 \times 10^{-3} \times P-0.052200 \times V-2.06924 \times 10^{-3} \times X+0.016146 \times Y \\
& -1.06297 \times 10^{-4} \times P \times V-7.67447 \times 10^{-6} \times P \times X-3.08705 \times 10^{-5} \times P \times Y \\
& +1.50649 \times 10^{-4} \times V \times X+4.67978 \times 10^{-4} \times V \times Y-1.57584 \times 10^{-5} \times X \times Y \\
& +2.20973 \times 10^{-6} \times P^{2}+1.35620 \times 10^{-3} \times V^{2}+2.27744 \times 10^{-5} \times X^{2}-4.08603 \times 10^{-4} \times Y^{2}
\end{aligned}
$$

\subsection{Effects of Process Parameters on Bending Angle}

The effects of parameters on the response are identified through the developed response surface model. Figure 7 (a) shows the response contour plot of the effect of the interaction between process variables and bending angle. From the figure, it can be seen that bending angle increases with laser power for a constant scanning speed. Conversely, bending angle decreases when scanning speed is increased at a fixed laser power. As scanning speed increases, interaction time between the workpiece and the laser beam decreases, resulting in reduced absorption of heat by the workpiece, leading to reduction in bending angle. Figure 7 (b) shows the response contour plot of the effects of the interaction between cut out geometric parameters and bending angle. It is observed from the figure, that bending angle is hardly affected by the cut out dimension along $\mathrm{x}$-direction while cut out dimension in $\mathrm{y}$-direction is kept constant. It also shows that bending angle decreases with increase in cut out dimension in y-direction while cut out dimension in $\mathrm{x}$-direction is kept constant. As cut out dimension in y-direction increases, interaction time between the workpiece and the laser beam decreases, resulting in reduced absorption of heat by the workpiece. Thus, the amount of bending decreases with increase in cut out dimension in y-direction. Figure 7 (c) shows the response surface plot of the interaction effect of parameters laser power and cut out in y-direction on bending angle. The response is consistent with what have already observed in Figure 7 (a) and (b). 

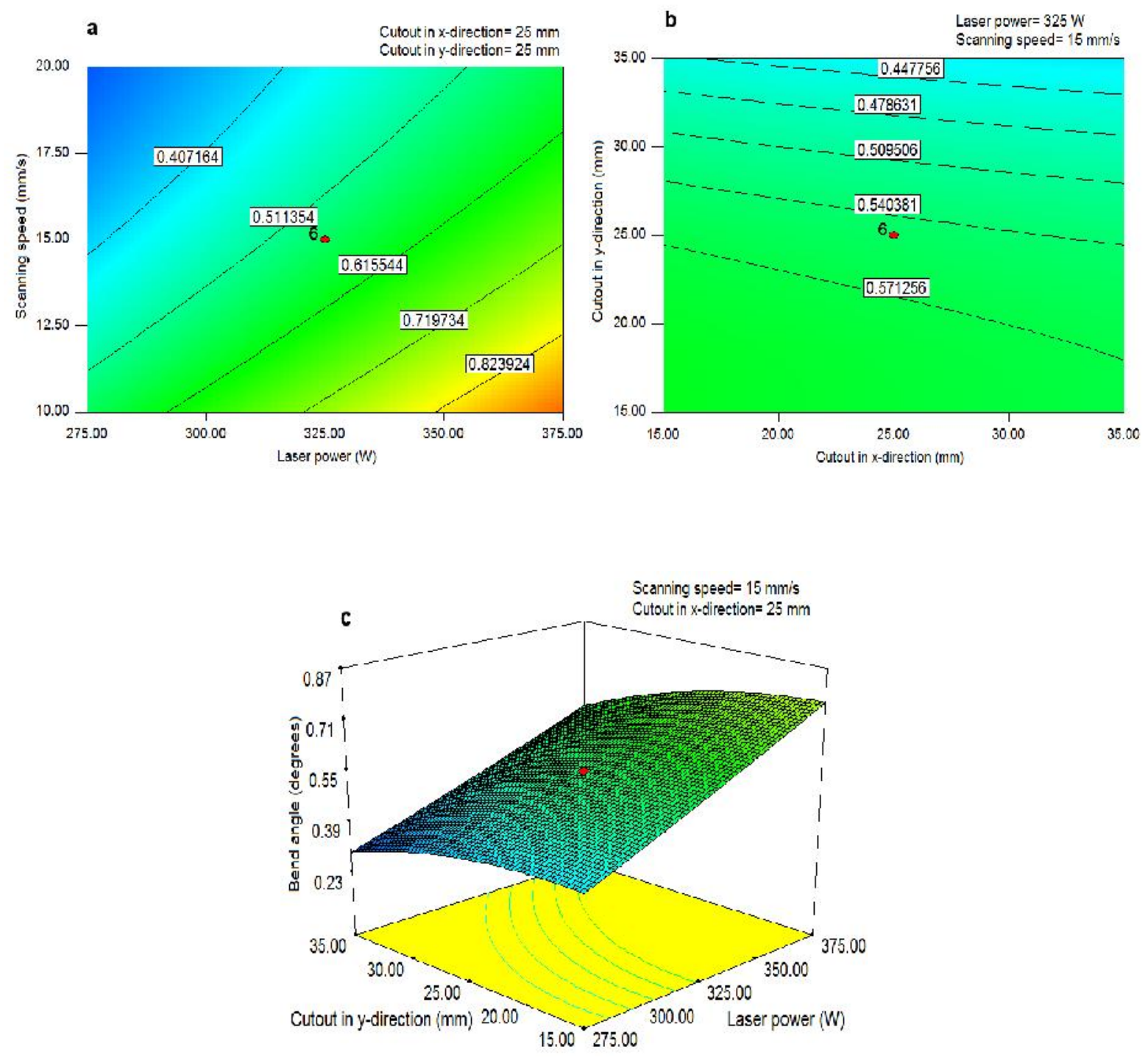

Figure 7: Contours and response surface plot showing the effects of input parameters on bending angle

\section{Artificial Neural Network Design}

Artificial neural network (ANN) is used to predict maximum temperature and bending angle. ANN is a multilayered architecture made up of one or more hidden layers placed between the input and output layers. In the present work, a multilayer feed-forward neural network with back-propagation learning algorithm is created to predict maximum temperature and bending angle. The input variables, namely, laser power, scanning speed and cut out dimensions are used for training of the network while output variables maximum temperature and bending angle are used for the present study to create the logical relationships between input variables and output variables. The neural network performance depends on the number of hidden layers and number of neurons in them. The network is trained with one and two number of hidden layers. The number of neurons and transfer function in each hidden layer is varied at the time of training. Thus, more than a few number of combinations are trained to choose the best combination with highest prediction accuracy. Six number of simulation data from out of 30 simulation results are used as test data. The selected simulations data for testing is marked in boldface in Table 2. The remaining 24 simulation data are selected for training the network. All the input and output variables are normalized between 0 and 1 to increase the accuracy of prediction and speed of the network. Finally, the input and output are denormalized after prediction. Matlab 2011a application code is used to develop and train the network. The selected structure of the neural network to predict maximum temperature are 4-6-5-1 (4 neurons in the input layer, 6 neurons in the first hidden layer, 5 neurons in the second hidden layer and 1 neuron in the output layer). The selected structure of the network is shown in Figure 8. The network training function TRAINLM is used for training the network, which is the fastest and highly recommended algorithm. The selected network is trained with learning rate of 0.05 , maximum number of epochs 5000, performance goal value of 0.0001 and maximum validation failure of 6 . The selected structure of the neural network 
to predict bending angle is 4-7-3-1. The selected structure of the network is shown in Figure 9. The network training function TRAINLM is used for training the network. The selected network is trained with learning rate of 0.05 , maximum number of epochs 5000, performance goal value of 0.0001 and maximum validation failure of 6 . The training is continued until the error reaches the performance goal or when the given number of epochs elapse.

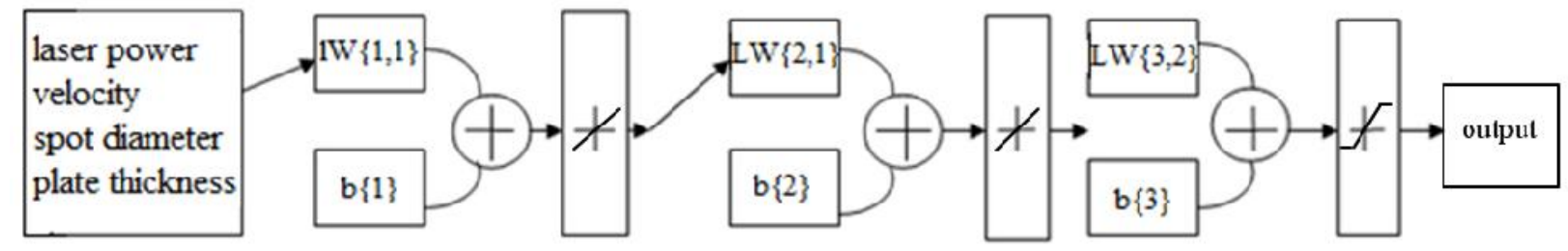

Figure 8: Structure of network used for prediction of maximum temperature

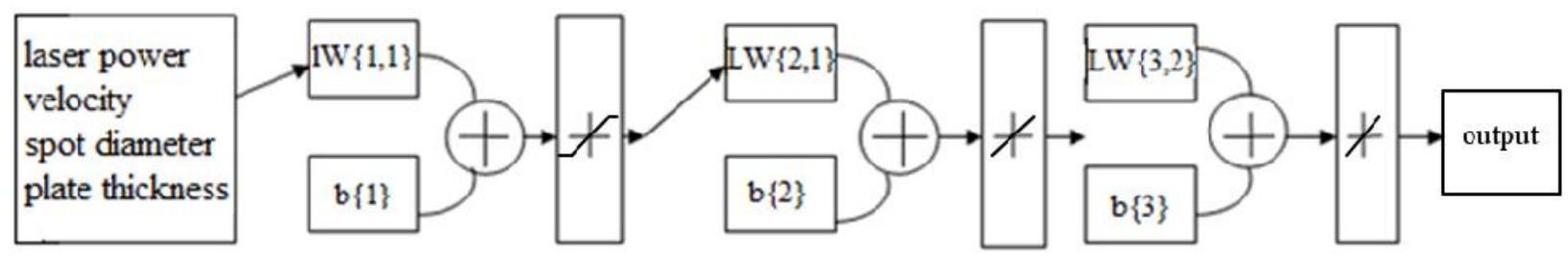

Figure 9: Structure of network used for prediction of bending angle

\section{Comparison of ANN and RSM Results and Discussion}

\subsection{Artificial Neural Network}

The most fitting network architecture is selected based on the minimum prediction error and a very high value of regression. The performance of the selected network to predict maximum temperature is satisfying with the mean squared error value of 3.2383e-5. The regression plot of output vs. target is also obtained with regression value of 0.990 at end of the training. For a best fit, the regression value should come to around 1. In training, the selected network architecture comes closest to 1 in comparison to other trained network architectures. The performance of the selected network to predict bending angle is satisfactory with regression value of 0.995 at the end of training. The accuracy of the selected network architecture is better portrayed through Figure 10.

\subsection{Accuracy of Neural Network and Regression Models}

The maximum temperature and bending angle of a rectangular AISI 304 plate with a rectangular cut out at its middle are predicted from predictive models i.e., neural network and response surface method, and predicted responses are compared based on their prediction accuracies. Outputs of neural network and regression model are compared with numerical simulation results of maximum temperature and bending angle for given input parameters, and the percent error in both cases are compared for evaluating accuracy and relative performance of the predictive models. The efficiency of the predictive models is calculated by Percentage error in prediction

$$
=\frac{\text { Numerical simulation output }- \text { Pr edicted output of } R S M \text { or ANN }}{\text { Numerical simulation result }} \times 100
$$

The performance of neural network and regression models are compared in terms of percent error (\%) for predicting the maximum temperature and bending angle of laser forming of rectangular AISI 304 plate having a rectangular cut out at its middle. The comparisons are made between simulation results and predicted results of neural network and regression models, as listed in Tables 7 and 8. It can be observed from these results that ANN predictive model and regression model are in close agreement with simulation results. 

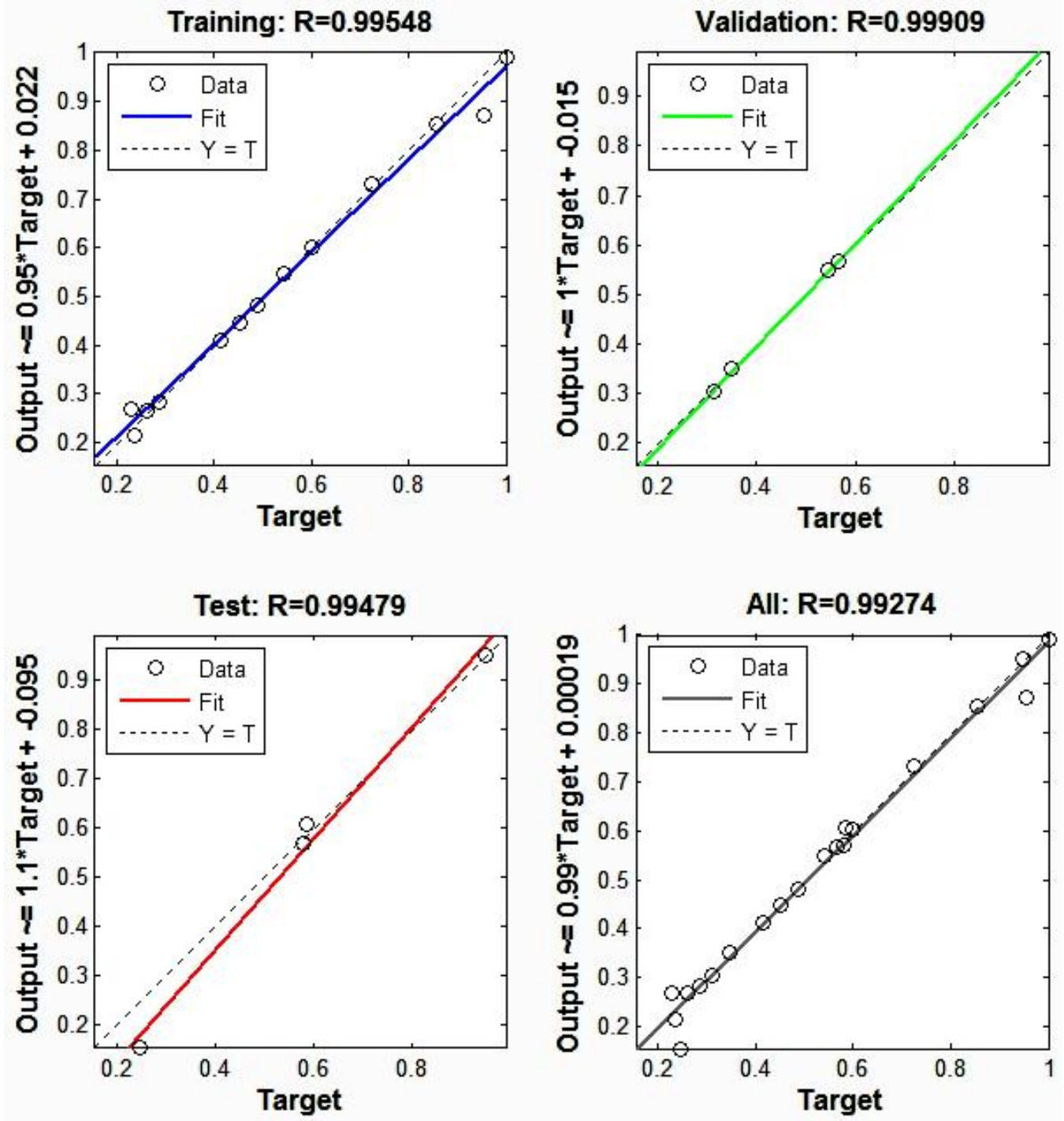

Figure 10: Selected network training regression plot for bending angle

Table 7: Comparison of simulation and prediction results for maximum temperature

\begin{tabular}{|c|c|c|c|c|c|c|c|c|c|}
\hline \multirow{2}{*}{$\begin{array}{l}\text { Sl. } \\
\text { No }\end{array}$} & \multirow{2}{*}{$\begin{array}{l}\mathrm{P} \\
(\mathrm{W})\end{array}$} & \multirow{2}{*}{$\begin{array}{l}V \\
(\mathrm{~mm} / \\
\mathrm{s})\end{array}$} & \multirow{2}{*}{$\begin{array}{l}\text { Cut out } \\
\text { dimen- } \\
\text { sion in } \\
\text { X-dir. } \\
(\mathrm{mm})\end{array}$} & \multirow{2}{*}{$\begin{array}{l}\text { Cut out } \\
\text { dimen- } \\
\text { sion in } \\
\text { y-dir. } \\
(\mathrm{mm})\end{array}$} & \multirow{2}{*}{$\begin{array}{l}\begin{array}{l}\text { Simula- } \\
\text { tion } \\
\text { result }\end{array} \\
\text { Actual } \\
\text { value } \\
\left(\phi_{a}\right)\end{array}$} & \multicolumn{2}{|c|}{ Regression model } & \multicolumn{2}{|l|}{ ANN result } \\
\hline & & & & & & $\begin{array}{l}\text { Predicted } \\
\text { value }\left(\phi_{b}\right)\end{array}$ & $\begin{array}{l}\text { Error (\%) } \\
\frac{\left(\phi_{a}-\phi_{b}\right)}{\left(\phi_{a}\right)} \times 100\end{array}$ & $\begin{array}{l}\text { Predicted } \\
\text { value }\left(\phi_{c}\right)\end{array}$ & $\begin{array}{l}\text { Error (\%) } \\
\frac{\left(\phi_{a}-\phi_{c}\right)}{\left(\phi_{a}\right)} \times 100\end{array}$ \\
\hline 1 & 325 & 15.0 & 25.0 & 25.0 & 1424 & 1424.88 & -0.062 & 1435.65 & -0.818 \\
\hline 2 & 375 & 20.0 & 15.0 & 15.0 & 1458 & 1452.34 & 0.388 & 1463.80 & -0.398 \\
\hline 3 & 325 & 15.0 & 43.2 & 25.0 & 1418 & 1412.15 & 0.413 & 1404.89 & 0.925 \\
\hline 4 & 275 & 10.0 & 15.0 & 35.0 & 1398 & 1405.90 & -0.565 & 1424.18 & -1.873 \\
\hline 5 & 375 & 10.0 & 15.0 & 35.0 & 1703 & 1709.86 & -0.403 & 1696.75 & 0.367 \\
\hline 6 & 275 & 10.0 & 35.0 & 15.0 & 1396 & 1400.94 & -0.354 & 1415.41 & -1.391 \\
\hline
\end{tabular}


Table 8: Comparison of simulation and prediction results for bending angle

\begin{tabular}{|c|c|c|c|c|c|c|c|c|c|}
\hline \multirow{2}{*}{$\begin{array}{l}\text { Sl. } \\
\text { No }\end{array}$} & \multirow{2}{*}{$\begin{array}{l}\mathrm{P} \\
(\mathrm{W})\end{array}$} & \multirow{2}{*}{$\begin{array}{l}\mathrm{V} \\
(\mathrm{mm} / \\
\mathrm{s})\end{array}$} & \multirow{2}{*}{$\begin{array}{l}\text { Cut out } \\
\text { dimen- } \\
\text { sion in } \\
\text { X-dir. } \\
(\mathrm{mm})\end{array}$} & \multirow{2}{*}{$\begin{array}{l}\text { Cut out } \\
\text { dimen- } \\
\text { sion in } \\
\text { x-dir. } \\
(\mathrm{mm})\end{array}$} & \multirow{2}{*}{$\begin{array}{l}\text { Simula- } \\
\text { tion } \\
\text { result } \\
\text { Actual } \\
\text { value } \\
\left(\phi_{d}\right)\end{array}$} & \multicolumn{2}{|c|}{ Regression model } & \multicolumn{2}{|l|}{ ANN result } \\
\hline & & & & & & $\begin{array}{l}\text { Predicted } \\
\text { value }\left(\phi_{e}\right)\end{array}$ & $\begin{array}{l}\text { Error }(\%) \\
\frac{\left(\phi_{d}-\phi_{e}\right)}{\left(\phi_{d}\right)} \times 100\end{array}$ & $\begin{array}{l}\text { Predicted } \\
\text { value }\left(\phi_{f}\right)\end{array}$ & $\begin{array}{l}\text { Error } \\
(\%) \\
\frac{\left(\phi_{d}-\phi_{f}\right)}{\left(\phi_{d}\right)} \times 100\end{array}$ \\
\hline 1 & 325 & 15.0 & 25.0 & 25.0 & 0.550 & 0.549 & 0.047 & 0.527 & 3.964 \\
\hline 2 & 375 & 20.0 & 15.0 & 15.0 & 0.600 & 0.609 & -1.523 & 0.578 & 3.885 \\
\hline 3 & 325 & 15.0 & 43.2 & 25.0 & 0.539 & 0.529 & 1.893 & 0.519 & 3.736 \\
\hline 4 & 275 & 10.0 & 15.0 & 35.0 & 0.457 & 0.453 & 0.809 & 0.447 & 2.103 \\
\hline 5 & 375 & 10.0 & 15.0 & 35.0 & 0.810 & 0.802 & 0.976 & 0.801 & 1.076 \\
\hline 6 & 275 & 10.0 & 35.0 & 15.0 & 0.566 & 0.584 & -3.169 & 0.549 & 3.123 \\
\hline
\end{tabular}

\subsection{Comparative Study of Simulated and Predicted Models}

The comparison plots of the numerical simulation data and prediction data of the maximum temperature and bending angle are shown in Figure 11 (a) and (b), respectively. It can be noticed from these figures that results obtained by both predicted models are in closer agreement with numerical simulation.
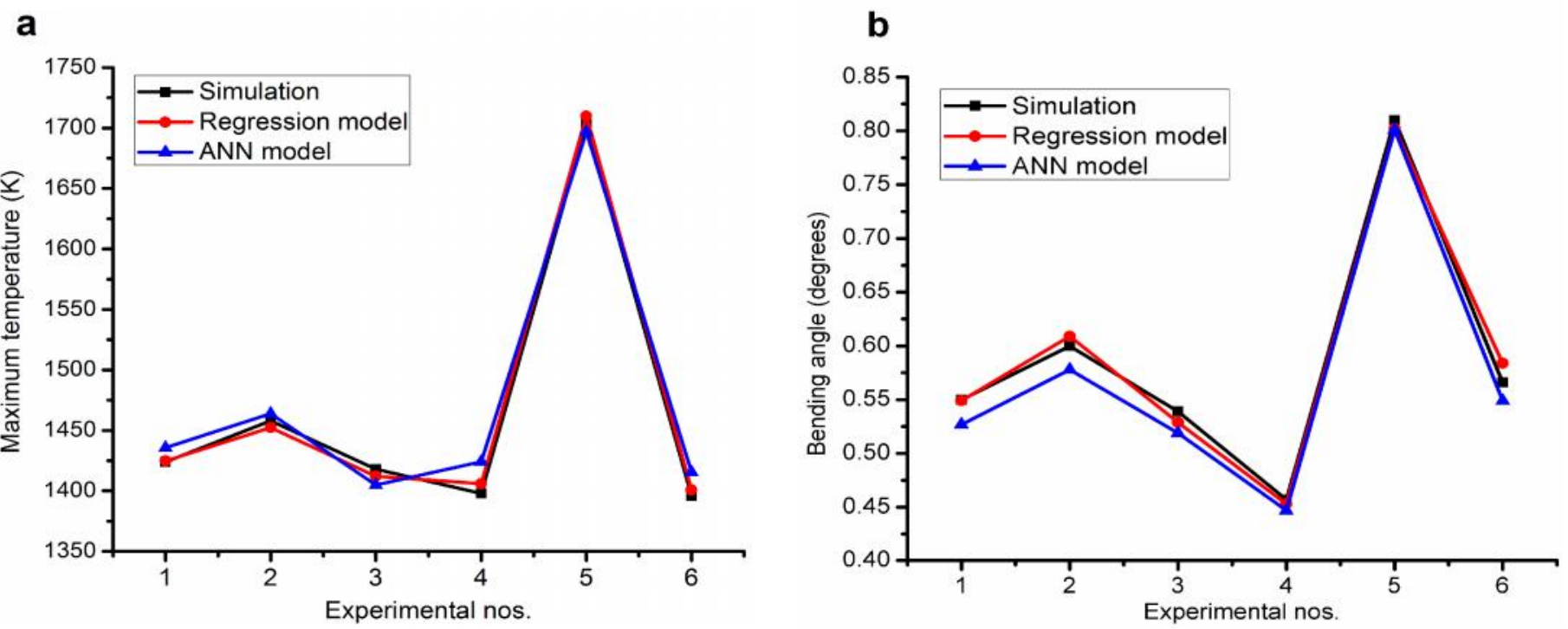

Figure 11: Comparison of simulation and predicted results for (a) maximum temperature, (b) bending angle

\section{Conclusion}

The present study investigates in considerable detail, laser bending of a rectangular AISI 304 plate with a rectangular cut out at its middle as it finds application in diverse industries. Following conclusions can be drawn from the present study using finite element method together with artificial neural network and response surface methodology:

1. The developed regression equation can predict responses effectively within limits of laser bending parameters used.

2. Maximum temperature increases with laser power and decreases with scanning speed. The maximum temperature does not depend much on the cut out dimensions.

3. Bending angle increases with laser power and decreases with scanning speed and it does not depend much on cut out dimension in x-direction. It is also noticed that bending angle decreases with increase in cut out dimension along ydirection.

4. A multiple regression model is developed and its performance is compared with the performance of the neural network model. Results obtained from these models are found to be in good agreement with numerical simulation. 
5. Simulation results generated out of the present work could be useful in implementing laser forming of AISI 304 plates with its end-use in process industry, aerospace, automotive and ship building industries etc. Simulation results indicate that bend angle decreases with increase in cut-out dimension along the laser scanning path.

6. To increase the magnitude of the bending angle, external cooling can be incorporated at the bottom of the plate and in depth studies in this direction may be taken up.

\section{Nomenclature \\ Symbols}
A
Absorption coefficient
C
Specific heat $(\mathrm{J} / \mathrm{kgK})$
$f_{r}$
Function of response
$h$
Natural convection coefficient $\left(\mathrm{W} / \mathrm{m}^{2} \mathrm{~K}\right)$
K
Thermal conductivity (W/mK)
$P \quad$ Laser power (W)
$q_{\text {conv }}$
Heat loss by convection per unit area $\left(\mathrm{W} / \mathrm{m}^{2}\right)$
$q_{\text {rad }}$
Heat loss by radiation per unit area $\left(\mathrm{W} / \mathrm{m}^{2}\right)$
Heat flux $\left(\mathrm{W} / \mathrm{m}^{2}\right)$
$r$
Distance from center of laser beam (m)
$R \quad$ Beam radius (m)
$T$
Time (s)
$t_{0}$
Initial time (s)
$T_{s} \quad$ Surface temperature (K)
$T_{0} \quad$ Surrounding temperature (K)
$T(r, t) \quad$ Temperature (K)
$T_{\max } \quad$ Maximum temperature (K)
$x_{1}, x_{2}, \ldots . x_{n} \quad$ Independent parameters
$y \quad$ Response
$V \quad$ Scanning velocity $(\mathrm{mm} / \mathrm{s})$
$X \quad$ Cut out dimension in $\mathrm{x}$-direction
$Y \quad$ Cut out dimension in y-direction
Greek symbols$$
\alpha_{b}
$$
$\sigma$
$\varepsilon_{e r}$
Bending angle
Coordinate in the reference configuration
Material density $\left(\mathrm{kg} / \mathrm{m}^{3}\right)$
Stefan Boltzmann constant $\left(\mathrm{W} / \mathrm{m}^{2} \mathrm{~K}^{4}\right)$
Emissivity
Prediction error 


\section{Operator}

$\nabla_{r} \quad$ Gradient operator

\section{References}

Acherjee B., Kuar A., Mitra S., Misra D., 2012. Modeling of laser transmission contour welding process using FEA and DoE. Optics \& Laser Technology. Vol. 44, pp.1281-1289.

Che J., Sheikh M., Li L., 2011. A study of the effect of laser beam geometries on laser bending of sheet metal by buckling mechanism. Optics and Laser Technology. Vol. 43, pp. 183-193.

Cheng P., Yao YL., Liu C., Pratt D., Fan Y., 2004. Analysis and prediction of size effect on laser forming of sheet metal. Transactions of the North American Manufacturing Research Institute of SME. Vol. 32, pp. 439-446.

Chen DJ., Wu SC., Li MQ., 2004. Studies on laser forming of Ti-6Al-4V alloy sheet. Journal of Materials Processing Technology. Vol. 152, No. 1, pp. 62-65.

Gollo H., Naeini M., Liaghat GH., Jelvani S., Torkamany MJ., 2010. A numerical and experimental study of sheet metal bending by pulsed Nd:Yag laser with DOE method. Advanced Materials Research. Vol. 83, No. 86, pp. 1076-1083.

Ji Z., Wu S., 1998. FEM simulation of the temperature field during the laser forming of sheet metal. Journal of Materials Processing Technology. Vol. 74, pp. 89-95.

Jung H.C., 2006. A study on laser forming processes with finite element analysis. PhD thesis, Christchurch, New Zealand.

Kyrsanidi An.K., Kermanidis Th.B., Pantelakis Sp.G., 1999. Numerical and experimental investigation of the laser forming process. Journal of Materials Processing Technology. Vol. 87, pp. 281 - 290.

Maji K., Pratihar D., Nath AK., 2013. Experimental investigations and statistical analysis of pulsed laser bending of AISI304 stainless steel sheet. Optics and Laser Technology. Vol. 49, pp. 18-27.

Montgomery DC., 2001. Design and analysis of experiments. 5th Ed., New York, Wiley.

Nadeem Q., Na., 2011. Deformation behavior of laser bending of circular sheet metal. Chinese Optics Letters. Vol. 9, No. 5, (Article No: 051402).

Paramasivan K., Das S., Misra D., 2014. A study on the effect of rectangular cut out on laser forming of AISI 304 plates. The International Journal of Advanced Manufacturing Technology. Vol. 72, pp. 1513-1525.

Shen H., Hu J., Yu X., Yao Z., 2012. The effects of cut-out on stress distribution and deformations in laser thermal adjustment. International Journal of Machine Tools \& Manufacture. Vol. 62, pp. 46-52.

Shi JW., Li LQ., Chen YB., Wang W., 2007. Numerical simulation of bending properties for sheet metal with different laser source modes. Zhongguo Jiguang/Chinese Journal of Laser. Vol. 34, No. 9, pp.1303-1307.

Shichun W., Jinsong Z., 2001. An experimental study of laser bending for sheet metals. Journal of Materials Processing Technology. Vol. 110, No. 2(9), pp. 160-163.

Venkadeshwaran K., Das S., Misra D., 2012. Bend angle prediction and parameter optimisation for laser bending of stainless steel using FEM and RSM. International Journal of Mechatronics and Manufacturing Systems. Vol. 5, No. 3/4, pp. 308-321.

Wu S., Ji Z., 2002. FEM simulation of the deformation field during the laser forming of sheet metal. Journal of Materials Processing Technology. Vol. 121, pp. 269-272.

Zahrani G., Marasi A., 2013. Experimental investigation of edge effect and longitudinal distortion in laser bending process. Optics \& Laser Technology. Vol. 45, pp. 301-307.

\section{Biographical notes}

K. Paramasivan is currently a Research Scholar in School of Laser Science \& Engineering, Jadavpur University, Kolkata, India. He completed his graduation in Mechanical Engineering from Government college of Engineering, Tirunelveli, India in 2009 and his post graduation in Computer Aided Design at Alagappa Chettiyar College of Engineering and Technology, Karaikkudi, India in 2011. His research interest includes finite element modeling and laser processing of materials.

Dr. Sandip Das is a faculty in the Department of Mechanical Engineering, Jadavpur University. He has 29 years of teaching experience. His fields of interest are thermal science, instrumentation and measurement and thermal-hydraulic studies in two-phase flow. Presently, he heads a couple of significant projects of national importance in the field of simulation of accident conditions in nuclear power plants.

Dr. Sundar Marimuthu specialises in laser/materials interaction and theoretical modelling of thermal interaction and fluid flow. He undertook post doctorial research on innovative laser processing of materials including laser cleaning and micro-machining of metals, ceramics and composites using short and ultra-short pulsed UV laser. At present, he is working as a lecturer in laser processing within the Wolfson School of Mechanical and Manufacturing Engineering at Loughborough University. His PhD concerned development of a supersonic nozzle assembly that, for the first time, allowed $60 \mathrm{~mm}$ thick mild steel to be cut using a small and controllable $900 \mathrm{~W} \mathrm{CO} 2$ laser.

Dipten Misra is the Director of School of Laser Science \& Engineering and a faculty in the department of Mechanical Engineering, Jadavpur University. He has 29 years of teaching experience. His research interests are heat and mass transfer, computational fluid dynamics and laser processing of materials.

Received April 2016

Accepted November 2016

Final acceptance in revised form November 2016 